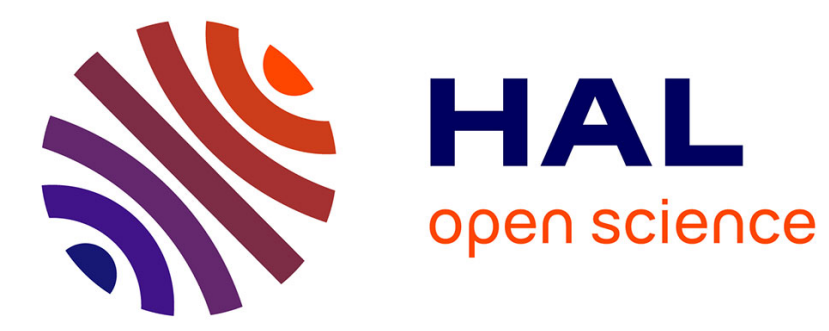

\title{
First case report of tDCS efficacy in severe chemsex addiction
}

Léo Malandain, Jean-Victor Blanc, Florian Ferreri, Timothée Giorgiadis, Sophie Mosser, Stéphane Mouchabac, Florence Thibaut

\section{To cite this version:}

Léo Malandain, Jean-Victor Blanc, Florian Ferreri, Timothée Giorgiadis, Sophie Mosser, et al.. First case report of tDCS efficacy in severe chemsex addiction. Dialogues in Clinical Neuroscience, 2020, 22 (3), pp.295 - 297. 10.31887/DCNS.2020.22.3/lmalandain . inserm-02973314

\section{HAL Id: inserm-02973314 https://www.hal.inserm.fr/inserm-02973314}

Submitted on 21 Oct 2020

HAL is a multi-disciplinary open access archive for the deposit and dissemination of scientific research documents, whether they are published or not. The documents may come from teaching and research institutions in France or abroad, or from public or private research centers.
L'archive ouverte pluridisciplinaire HAL, est destinée au dépôt et à la diffusion de documents scientifiques de niveau recherche, publiés ou non, émanant des établissements d'enseignement et de recherche français ou étrangers, des laboratoires publics ou privés. 


\title{
First case report of tDCS efficacy in severe chemsex addiction
}

\author{
Léo Malandain, MD; Jean-Victor Blanc, MD; Florian Ferreri, MD, PhD; \\ Timothée Giorgiadis, MD; Sophie Mosser, MD; Stéphane Mouchabac, MD; \\ Florence Thibaut, MD, PhD
}

Chemsex is an escalating public health issue among men who have sex with men, with potentially severe somatic and psychiatric consequences. Given the limited knowledge and lack of treatment recommendations available in this area, we proposed the use of noninvasive brain stimulation in order to reduce problematic chemsex behavior. This is the first openlabel case report of a positive effect of transcranial direct current stimulation (tDCS) in a patient who was complaining of severe chemsex addiction. Total disappearance of chemsex behavior occurred after 5 days of daily sessions of right prefrontal cortex stimulation and did not return after 8 months of follow-up. The strengthening of dorsolateral prefrontal cortex activity may have modulated limbic pathways and reduced incentive salience and craving of both sexual addiction and concomitant illicit drug use.

(c) 2020, AICH - Servier Group

Dialogues Clin Neurosci. 2020;22(3):295-297. doi:10.31887/DCNS.2020.22.3/lmalandain

Keywords: chemical sex; chemsex; sexual addiction; slamming; transcranial direct current stimulation (tDCS); virtual reality

\section{Introduction}

The term "chemsex," short for "chemical sex," refers to the voluntary use of specific psychoactive substances before or during planned sex to initiate, facilitate, intensify, or prolong sexual activity and pleasure. ${ }^{1}$ It mainly concerns men who have sex with men (MSM), often in the context of group sexual activity, or sex parties. The most commonly used drugs in Western Europe are crystal methamphetamine, $\gamma$-hydroxybutyrate or its prodrug $\gamma$-butyrolactone (GHB/GBL), mephedrone (4-methylmethcathinone [4MMC]), and, less often, other synthetic cathinones, cocaine, ketamine, or alkyl nitrites (poppers). In $75 \%$ of cases, people use a combination of these drugs, which can be snorted, swallowed, or smoked, but also injected (colloquially referred to as "slamming") or used via anal plug. ${ }^{2}$ Chemsex is associated with a high risk of human immunodeficiency virus (HIV) transmission, hepatitis
C, sexually transmitted diseases, nonconsensual sex, anal/rectal trauma, or penile abrasion. An increased risk of death was also reported in case of illicit drug associations. The estimated prevalence of chemsex in MSM ranges from 3\% to 32\%. ${ }^{3,4}$ Blomquist et $\mathrm{al}^{2}$ have found that of 3933 MSM recruited in the United Kingdom there was a 10\% prevalence of chemsex use in the past year and 25\% in the HIV-positive participants. The link between chemsex and hypersexual behavior or sexual addiction has been little studied, whereas it is widely described in clinical practice. ${ }^{5}$ To our knowledge in some countries, supportive health and community sector interventions were implemented in order to improve the wellbeing of this population, but thus far, there are no treatment guidelines for this combined addiction. ${ }^{6}$ Only one placebo-controlled study, including 28 homosexual or bisexual subjects diagnosed with sexual addiction, has compared the efficacy of $20 \mathrm{mg}$ to $60 \mathrm{mg}$ citalopram (selective serotonin reuptake inhibitor [SSRI]) with

Author affiliations: University Hospital Cochin (site Tarnier), Paris, France (Léo Malandain, Florence Thibaut); University Hospital Saint-Antoine, Paris, France (JeanVictor Blanc, Florian Ferreri, Timothée Giorgiadis, Sophie Mosser, Stéphane Mouchabac); Sorbonne University, Paris, France (Florian Ferreri); Faculty of Medicine Paris Descartes (University of Paris); INSERM U1266, Institute of Psychiatry and Neurosciences, Paris, France (Florence Thibaut). Address for correspondence: Prof Florence Thibaut, MD, PhD, Department of Psychiatry and Addictive Disorders, Hôpital Tarnier, 89 rue d'Assas, 75006 Paris, France (email: florence.thibaut@aphp.fr) 


\section{Free paper}

tDCS efficacy in severe chemsex addiction - Malandain et al

placebo. This study showed a significant reduction in sexual desire, frequency of masturbation, and use of pornography, but no changes in the number of partners. ${ }^{?}$ action). Paroxetine had been increased to $40 \mathrm{mg} / \mathrm{d}$, which was associated with the disappearance of depressive symptoms. However, the severe chemsex addiction remained unchanged.
Aside from that, interesting findings have been reported for transcranial direct current stimulation (tDCS) used to decrease craving and/or consumption in tobacco- and alcohol-use disorders. In most cases, the dorsolateral prefrontal cortex (DLPFC) was targeted with the anode over the right DLPFC in addiction/craving studies. ${ }^{8}$ To date, no tDCS study has been conducted in hypersexuality/sexual addiction or in chemsex addiction. Based on these previous positive results in substance addiction, we made the assumption that repeated stimulations of the DLPFC with tDCS would reduce craving in patients with hypersexual behavior associated with substance use and chemsex. We report the case of a patient with severe chemsex addiction who benefited from treatment by tDCS.

\section{Case report}

$\mathrm{Mr} \mathrm{S}$ is a 43-year-old patient who was hospitalized in a psychiatric ward in a context of suicidal crisis complicating a severe and recurrent major depressive disorder and substance-use disorder associated with slamming chemsex. He was previously hospitalized for a first major depressive episode in 2004, and then for relapses in 2016, 2017, and 2018 without any evidence of bipolar disorder. This patient had a history of recreational use of cocaine and GHB, as well as of misuse of benzodiazepines. He has also used other illicit drugs by snorting or by the intravenous route, including ketamine, synthetic cathinones, GHB, methamphetamines, and/or "speed" during sex with men for the last 3 years. Lately, he had been using intravenous synthetic cathinones ("slamming") to trigger sexual arousal (almost exclusively 3-methylmethcathinone/3-MMC or metaphedrone). He was undertaking chemsex every weekend (and this could last for up to 48 hours) plus onceor twice-weekly sessions that could sometimes last the whole night. Upon admission to hospital, his treatment included the following (concomitantly): paroxetine $20 \mathrm{mg} / \mathrm{d}$ (SSRI), cyamemazine $25 \mathrm{mg}$ on demand (used in France as a high-potency anxiolytic), alimemazine $10 \mathrm{mg} / \mathrm{d}$ (hypnotic), and risperidone $2 \mathrm{mg} / \mathrm{d}$ (second-generation antipsychotic with anti-impulsive baseline and day 5; similarly, the Cocaine Craving Questionnaire (CCQ) was adapted to assess 3-MMC craving; finally, chemsex craving was measured in a virtual environment with a visual analog scale (VAS) ranging from 0 ("no craving") to 10 ("most intense craving"). Before and after each tDCS session, we used virtual reality (VR) exposure with erotic/ pornographic photos selected by the patient (all photos were different). After five sessions of tDCS, the VAS score after VR stimulation decreased from 7 to 5, the CSB-13 from 37 to 27 (threshold: 35) and the CCQ from 43 to 28; and even more importantly, chemsex craving completely disappeared and did not return after 8 months of follow-up. Libido was still present, but our patient no longer had sex and/or 3-MMC use. No side effects were observed.

\section{Discussion}

This is the first report of a positive effect of tDCS in a patient who was complaining of severe chemsex addiction. Effectiveness is maintained in the medium term. The strengthening of DLPFC activity may have modulated limbic pathways and reduced incentive salience and craving, as suggested by Volkow. ${ }^{9}$

Although DLPFC stimulation is effective, it only covers part of the neural circuit involved in craving, which might be a limitation. Further studies must be conducted to confirm this promising result.

Acknowledgments/Disclosures: There are no potential conflicts of interest to report. The authors thank the reviewers for their helpful comments. 


\section{Free paper}

tDCS efficacy in severe chemsex addiction - Malandain et al

\section{References}

1. Sewell J, Cambiano V, Speakman A, et al. Changes in chemsex and sexual behaviour over time, among a cohort of MSM in London and Brighton: findings from the AURAH2 study. Int J Drug Policy. 2019;68:54-61.

2. Blomquist PB, Mohammed H, Mikhail A, et al. Characteristics and sexual health service use of MSM engaging in chemsex: results from a large online survey in England. Sex Transm Infect. 2020 Mar 5. Epub ahead of print. doi:10.1136/sextrans-2019-054345.

3. Rosińska M, Gios L, Nöstlinger C, et al. Prevalence of drug use during sex amongst MSM in Europe: results from a multi-site bio-behavioura survey. Int J Drug Policy. 2018;55:231-241.
4. Edmundson C, Heinsbroek E, Glass R, et al. Sexualised drug use in the United Kingdom (UK): a review of the literature. Int J Drug Policy. 2018;55:131-148.

5. Malandain L, Blanc JV, Ferreri F, Thibaut F. Pharmacotherapy of sexual addiction. Curr Psychiatry Rep. 2020;22(6):30. doi:10.1007/s11920-02001153-4.

6. Bourne A, Ong J, Pakianathan M. Sharing solutions for a reasoned and evidence-based response: chemsex/party and play among gay and bisexual men. Sex Health. 2018;15(2):99.

7. Wainberg ML, Muench F, Morgenstern J, et al. A double-blind study of citalopram versus placebo in the treatment of compulsive sexual behav- iors in gay and bisexual men. $J$ Clin Psychiatry. 2006;67(12):1968-1973.

8. Lefaucheur J-P, Antal A, Ayache SS, et al. Evidence-based guidelines on the therapeutic use of transcranial direct current stimulation (tDCS). Clin Neurophysiol. 2017;128(1):56-92.

9. Volkow ND, Boyle M. Neuroscience of addiction: relevance to prevention and treatment. Am J Psychiatry. 2018;175(8):729-740. 
